\title{
Environmental Footprint of Domestic Dogs and Cats
}

\author{
Jose Herrera-Camacho ${ }^{1}$, Eduardo Baltierra-Trejo ${ }^{2}$, Paul Adolfo Taboada-González \\ 3, Luisa Fernanda Gonzalez ${ }^{4}$, Liliana Márquez-Benavides 1,* \\ 1. Universidad Michoacana de San Nicolás de Hidalgo, Instituto de Investigaciones \\ Agropecuarias y Forestales, Av. San Juanito Itzícuaro S/N, Colonia San Juanito \\ Itzícuaro, C.P. 58240, Morelia Michoacán, México \\ 2. Centro de Investigación en Sustentabilidad Energética y Ambiental del Noreste \\ CISEAN, Universidad Autónoma del Noreste UANE, 87560, Matamoros Tamaulipas, \\ México.
}

3. Universidad Autónoma de Baja California, Facultad de Ciencias Químicas e Ingeniería, Calzada Universidad No. 14418, Mesa de Otay, C.P. 22390, Tijuana, Baja California, México,ptaboada@uabc.edu.mx

4. Universidad Distrital Francisco José de Caldas. Grupo de investigación en Estudios Ambientales (GEA), Carrera 7 No. 40B - 53, Bogotá D.C., Colombia, 1fgonzalezr@udistrital.edu.co

*Corresponding author:*1marquez@umich.mx

\section{Highlights}

- The is the first study that presents the environmental impacts generated by the maintenance of domestics pets.

- Life cycle analysis was used to assess the environmental footprint of domestic dogs and cats.

- Carbon footprint from the maintenance of both pet types had its greater contribution by the production of food.

\footnotetext{
Abstract

Mexico's inhabitants have approximately 7 million dogs and cats as pets, of which there is no accurate information about their environmental impacts as a result of their feeding and comfort requirements. The objective of this study is to compare the environmental footprint
} 
between a dog and a cat in a family environment. For this purpose, a life cycle analysis was performed including, among other factors, its feeding and waste management in one year of life. Different environmental indicators including the carbon footprint were considered. It was found that the equivalent $\mathrm{CO} 2$ emission of a dog is twice that estimated for a domestic cat and that the main contribution is due to the food production. The ecological footprint that is generated when satisfying the requirements for pet's well-being impacts in the environment contributes primarily to the carbon footprint.

Keywords: life cycle analysis, dogs; cats; carbon footprint; environmental pawprint

\section{Introduction}

Pets, particularly dogs (Canis lupus familiaris) and cats (Felix silvestris catus), play a role in the lives of people around the world. They not only have a companionship role, but they can also be used in activities as occupational therapy, speech therapy, physical rehabilitation (Cutt et al., 2007) or as guard and protection animals (Fuerstein and Terkel, 2008). However, the purpose that can be given to domestic pets is usually their "humanization", and the phrase "they are like family" among pet owners is frequent (Archer, 1997). The benefits of companion animals are diverse, but there may also be negative impacts. Noise, destructive behaviours, excrement, biting and overpopulation of domestic dogs and cats are some of the common problems that can result in stressors and difficulties in owners, neighbours, the community and pets (Cutt et al. 2007; Voith, 2009).

There are no studies or official information, but it is estimated that in Mexico exists one pet per 7 inhabitants, this is 5 million cats and 18 million dogs approximately. In the case of dogs, it is estimated that only $30 \%$ (about 5.4 million) have a home, ranking as the first country in Latin America in pet ownership (Morán-Rodríguez, 2012; Pacheco-Ríos, 2003; Sanchez-Acosta, 2011). A survey by the Mitofsky Survey House found that 55\% of Mexican households have at least one pet, of which $87 \%$ are dogs, and $23 \%$ are cats (Campos and Hernández, 2011).

The inclusion of pets in the daily lives of people in today's society leads to the owners have a particular attention to their needs. These include food, clothing, bedding and toys, which generate environmental loads that contribute to global warming and climate change (Di Cerbo et al., 2017), from production to disposal. 
Regarding pet food, $46 \%$ of owners in Mexico buy processed food for them (Campos and Hernández, 2011). According to the Mexican Association for Food Production, the estimated production in 2014 was between 650 thousand and 765 thousand tonnes in 2014. This amount was insufficient to cover the demand and was imported almost 25 thousand tonnes of food (Sanchez-Acosta, 2011) in that same year. In 2015, the pet food industry in Mexico estimated its profits at MXP \$42.6 billion (USD \$2.28 billion), with $96 \%$ of dog food at the market and cat at 4\%, 2016). In the USA, the food market in 2016 was calculated at USD $\$ 24.60$ billion (Pet-Food-Industry, 2016).

The Environmental Protection Agency (EPA) estimates that a medium-sized dog weighing $10 \mathrm{~kg}$, on average excretes about 250-350 g of faeces per day, which may vary depending on the size and its diet (NRCS-USDA, 2005). Considering the dog population in the cities of developed countries, this could mean that up to four percent of municipal waste corresponds to dog faeces (EPA, 2016). These residues can follow two ways: to be discarded directly to the drainage, which would at best reach a wastewater treatment plant, or be placed inside a plastic bag non-biodegradable and subsequently deposited in Landfills along with household waste.

In the case of domestic cats, the management of faeces is different. It is common that in some space of the residence a box with non-biodegradable inert sand (bentonite) is placed, which must be cleaned at least once a month. The waste generated (feaces + sand) is deposited in non-biodegradable plastic bags together with domestic waste which is disposed of in landfills. If the population of pets and their lifetime are considered, this practice can represent millions of tonnes of sand deposited in landfills.

As described, pet ownership represents a global market, whose industry requires the extraction of large quantities of inputs from nature and generates undesirable outputs as solid waste, chemical waste, and heat among others. However, there is insufficient and accurate information on the possible environmental impacts caused. For example, in Mexico, 98\% of the bentonite for the sandboxes comes mainly from Durango State, and from there it is taken to urban areas like Mexico City, at $850 \mathrm{~km}$ (SE, 2013). The environmental impact of transport has not been quantified. Ravilious (2009) indicated that the maintenance of a medium dog could leave an ecological footprint of 0.84 ha per year, that of a cat of 0.15 ha. But in the study cited only food production was considered. 
Researches have been conducted to quantify the contribution to climate change for human activities. For example, studies on environmental impacts generated from activities such as transport (Lin and Omoju, 2017, Bai et al., 2016), biofuels production (Papong et al., 2017), or Agriculture (He et al., 2016), among other topics. However, a daily activity such as the requirements of food and comfort of pets as dogs and cats not has been quantified. Therefore, the objective of the study is to compare the environmental footprint derived from a year in life between a dog and a cat in a domestic environment, using the methodology of Life Cycle Analysis (LCA).

\section{Methodology}

The LCA approach was used according to ISO-14040 (2006) and ISO-14044 (2006) standards. LCA methodology has four components as shown in Fig 1.

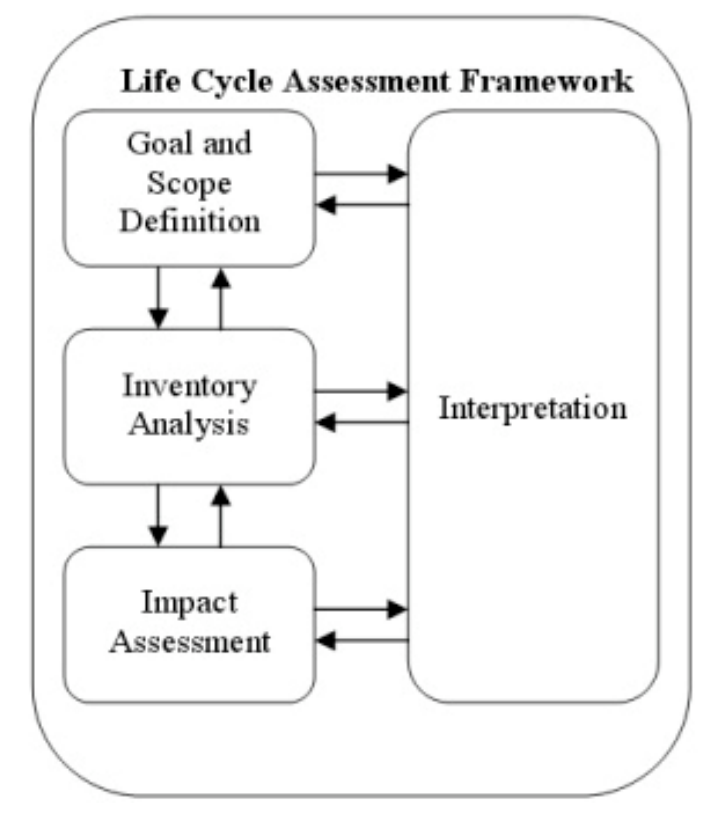

Fig. 1. LCA Framework according to ISO standards 14040 and 14044.

The first step was to set the study system's limits (Fig. 2). Afterwards, the scope and objectives were defined. The limit to compare the environmental footprint was a year of life of a domestic cat (Felix silvestris catus) and a dog (Canis lupus familiaris). The functional unit of this study was defined as "enjoying the companionship of a domestic pet - dog or cat - with physical well-being and health of the animal". The reference flow was defined as one year of the life of the pet in the healthy adult state, attending to the medical recommendations 
of the measurement of the food provided according to its weight and age. The study assumes the following conditions for domestic pets in a middle-class household in México: (a) Monthly changing the sand for the cat's litter box. (b) Each pet has a bed or own resting place. (c) The collection of dog faeces is carried out using a disposable plastic bag. (d) The adult dog weight is $10 \mathrm{~kg}$, and the adult cat weight is $4 \mathrm{~kg}$.

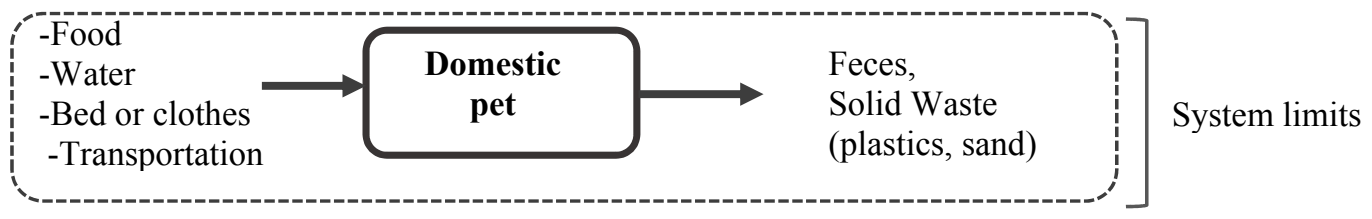

Fig. 2. Limits of the study system to maintain the physical well-being of a domestic pet.

\subsection{Inventory Analysis}

The data used in the LCA was obtained from the literature, using average normal physiological values for cats and dogs (weight excrement, the amount of food required, among others). Two types of sand for cat were considered: the first one, 100\% biodegradable, from Germany and the second one, an inert (bentonite). SimaPro 8.0 software with Ecoinvent 3.0 database was used to obtain the environmental footprint through the life-cycle impact assessment, considering a mid-point impact analysis using the ReciPe method to calculate the impact categories. Table 1 shows the different impact categories considered.

Table 1. Mid-point environmental impact categories.

\begin{tabular}{lcc}
\hline Category & Symbol & Unit \\
\hline Climate change & $\mathrm{CC}$ & $\mathrm{kg} \mathrm{CO}$ eq \\
Soil Acidification & $\mathrm{SA}$ & $\mathrm{kg} \mathrm{SO}$ eq \\
Marine Eutrophication & $\mathrm{ME}$ & $\mathrm{kg} \mathrm{N}$ eq \\
Human toxicity potential & $\mathrm{HTP}$ & $\mathrm{kg} 1,4-\mathrm{DB}$ eq \\
Formation of particulate matter & FPM & $\mathrm{kg} \mathrm{PM} 10$ eq \\
Terrestrial ecotoxicity & $\mathrm{TE}$ & $\mathrm{kg} 1,4-\mathrm{DB}$ eq \\
Ecotoxicity of fresh water & EFW & $\mathrm{kg} \mathrm{1,4-DB} \mathrm{eq}$ \\
Radiative Ionization & $\mathrm{RI}$ & $\mathrm{kBq} \mathrm{U}{ }^{235} \mathrm{eq}$ \\
\hline
\end{tabular}




\begin{tabular}{lcc}
\hline Occupation of agricultural land & OAL & $\mathrm{m}^{2}$ \\
Occupation of urban land & OUL & $\mathrm{m}^{2}$ \\
Soil transformation & ST & $\mathrm{m}^{2}$ \\
Water Depletion & WD & $\mathrm{m}^{3}$ \\
Metal depletion & MD & $\mathrm{kg} \mathrm{Fe} \mathrm{eq}$ \\
Fossil Fuel Depletion & FFD & $\mathrm{kg}$ oil eq \\
\hline
\end{tabular}

\section{Results \& discussion}

\subsection{Inventory data}

The comparison of the environmental footprint of pets was developed comparing the demand for resources necessary to comply with the functional unit. Fig. 3 shows the result of the estimated annual resource use allocated for the maintenance of 1000 domestic pets. The entry of resources into the study system evidenced that the demand for food and water was more than double for the dog, due just to its physiological requirements corresponding to the weight of $10 \mathrm{~kg}$ of live weight. However, the output of the system regarding the waste management, excrement and debris, showed that the cat produced three times more due to the use of sand. 

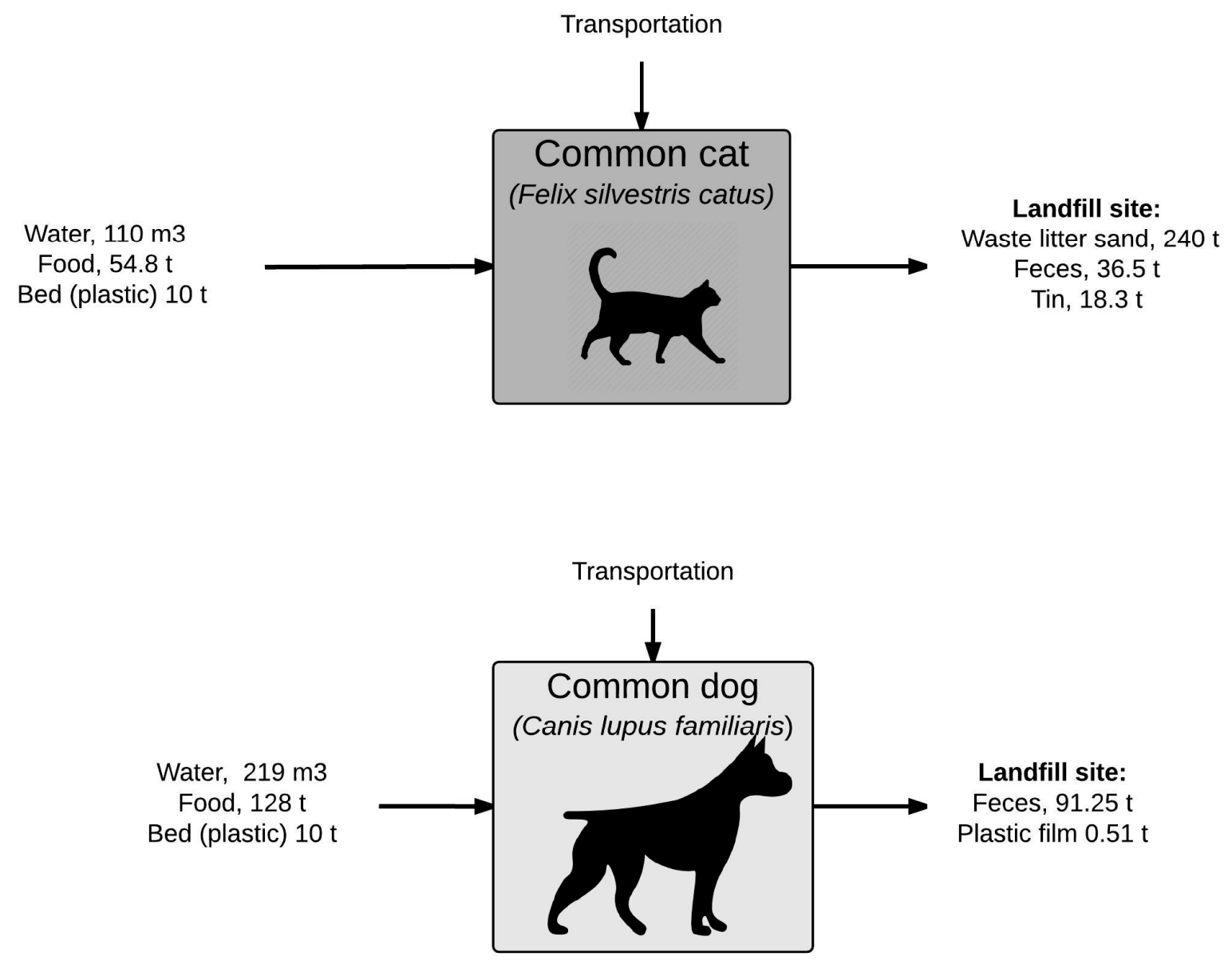

Fig. 3. Use of resources in annual household pet maintenance (Calculation basis: 1000 pets per annum).

\subsection{Midpoint impact categories}

The Life Cycle Analysis (LCA) approach allows for an overall consideration of a process or a product. Impact assessment takes into account the impact categories for inputs and outputs within the boundaries of a system. In general, for LCA categories related to inputs are the depletion of natural resources and the change of land use. The categories related to the outputs include climate change or human ecotoxicity, among others.

Table 2 shows the estimated midpoint impact categories and their respective contribution for the studied species. In general, dogs had a greater participation in the categories of environmental impact, although in both cases is due to food production. It should be pointed out that it is not that dog food has a greater impact in itself, but that is due to the difference 
in the quantities of food required by each pet type; 128 tonnes for dogs and 54.8 tonnes for cats (Fig. 3).

Table 2. Comparison of midpoint impact categories for annual domestic pet maintenance.

\begin{tabular}{|c|c|c|c|c|c|}
\hline \multicolumn{6}{|c|}{ Domestic cat (Felix silvestris catus) } \\
\hline $\begin{array}{l}\text { Impact } \\
\text { category }\end{array}$ & $\begin{array}{c}\text { Food } \\
\text { production }\end{array}$ & Plastic & Transportation & Waste & Total \\
\hline $\mathrm{CC}$ & 860 & 30 & 44 & 8 & $941 \mathrm{~kg} \mathrm{CO}_{2}$ eq \\
\hline SA & 15 & & & & $16 \mathrm{~kg} \mathrm{SO}_{2} \mathrm{eq}$ \\
\hline $\mathrm{ME}$ & 6 & & & & $6 \mathrm{~kg} \mathrm{~N} \mathrm{eq}$ \\
\hline HTP & 16 & 8 & 16 & & $41 \mathrm{~kg} \mathrm{1,4-DB} \mathrm{eq}$ \\
\hline FPM & 2 & & & & $2 \mathrm{~kg} \mathrm{MP} 10$ eq \\
\hline TE & 17 & & & & $17 \mathrm{~kg} \mathrm{1,4-DB} \mathrm{eq}$ \\
\hline EFW & 3 & & & & $4 \mathrm{~kg} 1,4-\mathrm{DB}$ eq \\
\hline RI & 7 & 4 & 3 & & $15 \mathrm{kBq} U 235 \mathrm{eq}$ \\
\hline OAL & 714 & 2 & & & $717 \mathrm{~m}^{2}$ \\
\hline OUL & & & 2 & & $3 \mathrm{~m}^{2}$ \\
\hline $\mathrm{ST}$ & 5 & & & & $5 \mathrm{~m}^{2}$ \\
\hline WD & 6 & & & & $7 \mathrm{~m}^{3}$ \\
\hline MD & & 1 & 2 & & $4 \mathrm{~kg} \mathrm{Fe} \mathrm{eq}$ \\
\hline FFD & 63 & 19 & 15 & 2 & $98 \mathrm{~kg}$ oil eq \\
\hline \multicolumn{6}{|c|}{ Domestic dog (Canis lupus familiaris) } \\
\hline $\begin{array}{l}\text { Impact } \\
\text { category }\end{array}$ & $\begin{array}{c}\text { Food } \\
\text { production }\end{array}$ & Plastic & Transportation & Waste & Total \\
\hline $\mathrm{CC}$ & 2006 & 30 & 8 & 17 & $2061 \mathrm{~kg} \mathrm{CO} 2 \mathrm{eq}$ \\
\hline SA & 36 & & & & $36 \mathrm{~kg} \mathrm{SO} 2 \mathrm{eq}$ \\
\hline $\mathrm{ME}$ & 14 & & & & $14 \mathrm{~kg} \mathrm{~N}$ eq \\
\hline HTP & 38 & 8 & 3 & & $49 \mathrm{~kg} 1,4-\mathrm{DB}$ eq \\
\hline FPM & 5 & & & & $5 \mathrm{~kg} \mathrm{MP}_{10} \mathrm{eq}$ \\
\hline TE & 39 & & & & $39 \mathrm{~kg} \mathrm{1,4-DB} \mathrm{eq}$ \\
\hline EFW & 7 & & & & $7 \mathrm{~kg} 1,4-\mathrm{DB}$ eq \\
\hline RI & 17 & 4 & & & $22 \mathrm{kBq} U 235 \mathrm{eq}$ \\
\hline OAL & 1665 & 2 & & & $1668 \mathrm{~m}^{2}$ \\
\hline ST & 12 & & & & $12 \mathrm{~m}^{2}$ \\
\hline WD & 15 & & & & $16 \mathrm{~m}^{3}$ \\
\hline $\mathrm{ME}$ & 1 & 1 & & & $3 \mathrm{~kg} \mathrm{Fe} \mathrm{eq}$ \\
\hline FFD & 146 & 19 & 4 & 1 & $168 \mathrm{~kg}$ oil eq \\
\hline
\end{tabular}

Total sums may not coincide due to rounding of decimals. Calculation basis: 1 pet 
The preponderant environmental impact of food production is consistent across other species. For example, for egg production soybean and maize production occupies $70 \%$ in impact categories (Ghasempour and Ahmadi, 2016). The pork food production as a hotspot within the pig breeding process in Galicia, mainly due to the import of grains from Ukraine, Argentina, USA and Brazil (Noya et al., 2017). Nonetheless, animal food is also considered a significant sink for human food waste with environmental and health impacts (Salemdeeb et al., 2017).

\subsection{Carbon footprint}

It is important to consider the particular implications of the inputs and outputs of the system. For example, in the case of the carbon footprint of maintaining a domestic pet, as mentioned above, the largest amount of $\mathrm{CO} 2 \mathrm{eq}$ emissions are associated with industrial food production. However, the pet-owner is for the most part limited to influence the process of food production itself. Even so, there are other decisions that as a consumer can take in an informed way. Table 3 shows the comparison of domestic dog and cat carbon footprint. In the cat case, two options were considered: using 100\% biodegradable sand made in Germany or using inert sand (Bentonite Sodium) produced in Durango, Mexico. In both cases, materials are carried to México City (central México). Contrary to expectations, transcontinental maritime transportation had a limited estimated contribution, whereas land transportation of $240 \mathrm{t}$ of sand impacts ten times more on climate change. Regarding the final disposal in the sanitary landfill, the carbon footprint of $100 \%$ biodegradable sand is 11 times greater than that of inert sand. Since the obtained results depended on the weight of the species concerned, it is important to mention that the standardised results at $1 \mathrm{~kg}$ of weight correspond to 206 tonnes of CO2 eq for 1000 dogs in an annual maintenance and 240 tonnes of $\mathrm{CO} 2$ eq per 1000 cats. It is evident then that the transportation of the discarded cat litter sand is responsible for the difference. 
Table 3. Household pet carbon footprint annual contribution.

\begin{tabular}{|c|c|c|c|}
\hline \multirow[t]{3}{*}{ PROCESS } & \multirow{2}{*}{ Dog } & \multicolumn{2}{|c|}{ Cat } \\
\hline & & Option A & Option B \\
\hline & \multicolumn{3}{|c|}{$\mathrm{CO}_{2}$ eq $(\mathrm{t} /$ year $)$} \\
\hline \multicolumn{4}{|l|}{ Feeding } \\
\hline Use of potable water & 0.07 & 0.03 & 0.03 \\
\hline Food production & 2,010 & 860 & 860 \\
\hline \multicolumn{4}{|l|}{ Clothing or beds } \\
\hline Plastic production & 29.6 & 29.6 & 29.6 \\
\hline \multicolumn{4}{|l|}{ Transportation } \\
\hline Food & 4.3 & 1.8 & 1.8 \\
\hline \multicolumn{4}{|l|}{ Unused litter sand } \\
\hline Land route & -- & 32.4 & 28.8 \\
\hline Maritime & -- & 3.8 & -- \\
\hline Solid waste to the local landfill & 3.96 & 13.1 & 13.1 \\
\hline Subtotal & 8.25 & 51.1 & 43.7 \\
\hline \multicolumn{4}{|l|}{ Waste to the local landfill } \\
\hline Feces & 17 & 6.8 & 6.8 \\
\hline Used litter sand & - & $14.9 \mathrm{a}$ & $1.27 \mathrm{~b}$ \\
\hline Plastic film (bags) & 0.04 & - & - \\
\hline Tin & -- & 0.048 & 0.048 \\
\hline Subtotal & 17.04 & 21.7 & 8.1 \\
\hline Total & $2,060.0$ & 962.5 & 941.4 \\
\hline
\end{tabular}

A. $100 \%$ biodegradable sand, transported by sea from Germany to Tamaulipas, Mexico, and then to México City.

B. Inert domestic litter sand (Sodium Bentonite), produced in Durango, Mexico and transported to México City.

Calculation basis: 1000 pets

Regular litter cat sand or sodium bentonite has particular physicochemical properties. With a density of $780 \mathrm{~kg} / \mathrm{m} 3$, the requirements for 1000 cats annually demands a space of $307 \mathrm{~m}^{3}$ at the local landfill. Götze et al. (2016) studied the physicochemical characteristics of the domestic waste in Danish households. The content of the litter sandbox was reported in the category of "Glass and inerts" and was the residue with the highest concentrations of $\mathrm{Al}, \mathrm{Be}$, $\mathrm{Co}, \mathrm{Ge}, \mathrm{Fe}, \mathrm{Hg}, \mathrm{Nb}, \mathrm{Pb}$, Th, and even $\mathrm{U}$. The presence of rare-earth elements such as 
neodymium $(\mathrm{Nd})$ or precious metals $(\mathrm{Au}$ and $\mathrm{Ag})$ in residues had only been associated with electronic waste in incineration plants (Morf et al., 2013).

Some alternative materials for use in the cat sandbox include those derived from food materials (wheat, corn, walnut). However, there are complaints about binder properties or about their propensity to create insects. Other proposals are pellets derived from lignocellulosic materials such as grass, pine, corn or combination of those, with better binder properties, but with reported limited ability to control odours (Vaughn et al., 2011; Vaughn et al., 2013). Finally, the use of diatomaceous earth for odour or insect control is also reported (Korunic, 1998) and might be a useful addition for cat litter sandboxes. The scarcity of reports on the natural alternative material for cat sandboxes points out a neglected area of research, where sustainability is urgently needed.

\subsection{Environmental footprint}

The aggregate of midpoint impact categories shown in Table 2 indicates the environmental footprint for studied pets. The impact categories are not comparable since they are represented in different units. However, the comparison between species is possible. The findings at other impact categories are shown below.

\section{Soil acidification (SA)}

SA is characterised by changes in the chemical properties of soils by the addition of nutrients in acid form. The calculus with the ReCiPE method estimated that the food production for maintenance of a cat in one year impacted 56\% less than the food for dogs (16 kg SO2 eq / $36 \mathrm{~kg} \mathrm{SO} 2 \mathrm{eq}$ ). To contextualize these values, the production potential of $1 \mathrm{~kg}$ of wheat flour, $1 \mathrm{~kg}$ of sugar and $1 \mathrm{~kg}$ of tomatoes, it is $6.9,6.0$ and $7.2 \mathrm{~kg} \mathrm{SO} 2 \mathrm{eq}$, respectively (Mogensen et al., 2009).

\section{Human toxicity potential (HTP)}

The estimated HTP is similar for both species (Table 2), measured in units of 1-4 dichlorobenzene equivalent. In both cases, the potential for human toxicity is distributed between food production, plastic production and transportation. This category of impact is 
often related to the emission of pollutants (e.g. heavy metals) and their effect on human health: tolerable concentrations in water and air or acceptable daily intake. Both species have lower toxicity potentials than found for other products, for instance, HTP for the production of 1 tonne of fish (live weight) has been reported between 639 and $3340 \mathrm{~kg}-1,4-\mathrm{DB}$ eq, mostly related to food production (Ayer and Tyedmers, 2009). Similarly, HTP estimated from rice production has been reported between 327 and $1801 \mathrm{~kg}$ 1,4-DB eq (Khoshnevisan et al., 2014).

\section{Fossil Fuel Depletion (FFD)}

FFD was revealed as a category of impact throughout the life cycle of the species studied. $64 \%$ of FFD for the cat was due to the production of food, in the case of the dog, this corresponded to $86 \%$. The transportation for the cat input case represented $15 \%$ of the FFD potential, while for the other species this represented only 11\% (Tongpool et al., 2012).

\section{Conclusions}

For the first time, the environmental impacts of pet (dog and cat) ownership are described using the LCA methodology. It was found that when satisfying the requirements for pet's well-being, the impacts in the environment contributes widely to the carbon footprint.

Knowing the environmental footprint of the various products on the market could allow consumers to make a better choice of the products they buy for their pets, while companies may consider other ways to obtain or manufacture the inputs. However, the ecological footprint of pet animals is only part of the problem, and the environmental impacts of abandoned animals on the streets could be bigger than those who have an owner.

\section{Acknowledgements}

The authors gratefully acknowledge the contribution of the referees on commenting this paper.

\section{References}

Archer, J., 1997. Why do people love their pets?. Evol. Hum. Behav. 18, 237-259. dx.doi.org/10.1016/S0162-3095(99)80001-4. 
Ayer, N.W., Tyedmers, P.H., 2009. Assessing alternative aquaculture technologies: life cycle assessment of salmonid culture systems in Canada. J. Clean. Prod. 17, 362373. doi.org/10.1016/j.jclepro.2008.08.002.

Bai, A., Jobbágy, P., Popp, J., Farkas, F., Grasselli, G., Szendrei, J., Balogh, P., 2016. Technical and environmental effects of biodiesel use in local public transport. Transp. Res. Part. Transp. Environ. 47, 323-335. doi:10.1016/j.trd.2016.06.009.

Campos, R., Hernández, A.M., 2011. México: las mascotas en nuestros hogares, Encuesta nacional en viviendas. Consulta Mitofsky, Ciudad de México, pp. 215-218. http://consulta.mx/index.php/estudios-e-investigaciones/mexico-opina/item/577mexico-las-mascotas-en-nuestros-hogares).

Cutt, H., Giles-Cortia, B., Knuimana, M., Burke, V., 2007. Dog ownership, health and physical activity: A critical review of the literature. Health Place. 13, 261-272. doi.org/10.1016/j.healthplace.2006.01.003.

Di Cerbo, A., Morales-Medina, J.C., Palmieric, B, Pezzutod, F., Coccoe, R., Flores, G., Iannittig, T., 2017. Functional foods in pet nutrition: Focus on dogs and cats. Res. Vet. Sci.112, 161-166. doi.org/10.1016/j.rvsc.2017.03.020.

EPA, 2016. Monitoring and Evaluating Nonpoint Source Watershed Projects: Overview of the Nonpoint Source Problem, in: Secondary EPA (Ed.), Secondary Monitoring and Evaluating Nonpoint Source Watershed Projects: Overview of the Nonpoint Source Problem. Environmental Protection Agency, U.S.A. https://www.epa.gov/sites/production/files/201602/documents/chapter_1_draft_aug_2014.pdf.).

Feuerstein, N., Terkel J., 2008. Interrelationships of dogs (Canis familiaris) and cats (Felis catus L.) living under the same roof. Appl. Anim. Behav. Sci.113, 150-165. doi: 10.1016/j.applanim.2007.10.010.

Ghasempour, A., Ahmadi, E., 2016. Assessment of environment impacts of egg production chain using life cycle assessment. J. Environ. Manage. 183, 980-987. doi:10.1016/j.jenvman.2016.09.054.

Götze, R., Boldrin, A., Scheutz, C., Astrup, T.F., 2016. Physico-chemical characterisation of material fractions in household waste: Overview of data in literature. Waste Manage. 49, 3-14. doi: 10.1016/j.wasman.2016.01.008.

He, X., Qiao, Y., Liu, Y., Dendler, L., Yin, C., Martin, F., 2016. Environmental impact assessment of organic and conventional tomato production in urban greenhouses of Beijing city, China. Special Volume: Transitions to Sustainable Consumption and Production in Cities. J. Clean. Prod. 134, 251-258. doi:10.1016/j.jclepro.2015.12.004.

ISO-14040, 2006. Environmental management-Life cycle assessment-Principles and framework. European Committee for Standardization, in: Secondary ISO-14040 (Ed.), Secondary Environmental management-Life cycle assessment-Principles and framework. European Committee for Standardization, Geneva, Switzerland.).

ISO-14044, 2006. Environmental management - Life cycle assessment - Requirements and Guidelines, in: Secondary ISO-14044 (Ed.), Secondary Environmental management - Life cycle assessment - Requirements and Guidelines. International Organization for Standardization, Geneva, Switzerland.).

Khoshnevisan, B., Rajaeifar, M.A., Clark, S., Shamahirband, S., Anuar, N.B., Shuib, N.L.M., Gani, A., 2014. Evaluation of traditional and consolidated rice farms in 
Guilan Province, Iran, using life cycle assessment and fuzzy modeling. Sci. Total Environ. 481, 242-251. doi: 10.1016/j.scitotenv.2014.02.052.

Korunic, Z., 1998. Review: Diatomaceous earths, a group of natural insecticides. J. Stored Prod. Res. 34, 87-97. doi.org/10.1016/S0022-474X(97)00039-8.

Lin, B., Omoju, O.E., 2017. Does private investment in the transport sector mitigate the environmental impact of urbanisation? Evidence from Asia. J. Clean. Prod. 153, 331-341. doi:10.1016/j.jclepro.2017.01.064.

Mogensen, L., Hermansen, J.E., Halberg, N., Dalgaard, R., Vis, J.C., Smith, B.G., 2009. Life cycle assessment across the food supply chain. Sustainability in the food industry, 115-144. doi: 10.1002/9781118467589.ch5

Morán-Rodríguez, L.E., 2012. Proponen solución al problema de los perros callejeros, Ciencia UNAM. Dirección General de Divulgación de la Ciencia, Ciudad de México. http://ciencia.unam.mx/leer/109/Proponen_solucion_al_problema_de_los_perros_ca 1lejeros.).

Morf, L.S., Gloor, R., Haag, O., Haupt, M., Skutan, S., Di Lorenzo, F., Böni, D., 2013. Precious metals and rare earth elements in municipal solid waste-sources and fate in a Swiss incineration plant. Waste Manage. 33, 634-644. doi: : 10.1016/j.wasman.2012.09.010.

Noya, I., Villanueva-Rey, P., González-García, S., Fernandez, M.D., Rodriguez, M.R., Moreira, M.T., 2017. Life Cycle Assessment of pig production: A case study in Galicia. J. Clean. Prod. 142, 4327-4338. doi: 10.1016/j.jclepro.2016.11.160.

NRCS-USDA, 2005. Composting Dog Waste, in: Secondary NRCS-USDA (Ed.), Secondary Composting Dog Waste. United States Department of Agriculture, Natural Resources Conservation Service, 1-11. https://www.nrcs.usda.gov/Internet/FSE.../nrcs142p2_035763.pdf. (21/04/2017).

Pacheco-Ríos, A., 2003. Mascotas en los hogares: enfermedades de los niños adquiridas por convivencia con animales. Enf. Infec. y Micro. 23, 137-148.

Papong, S., Rewlay-ngoen, C., Itsubo, N., Malakul, P., 2017. Environmental life cycle assessment and social impacts of bioethanol production in Thailand. J. Clean. Prod. 157, 254-266. doi:10.1016/j.jclepro.2017.04.122.

Pet-Food-Industry, 2016. Changing lifestyles are expected to aid pet food market growth, in: Secondary Pet-Food-Industry (Ed.), Secondary Changing lifestyles are expected to aid pet food market growth. Pet Food Industry, U.S.A. http://www.petfoodindustry.com/articles/6224-us-pet-food-market-forecast-at-us30billion-by-2022.).

Ravilious, K., 2009. How green is your pet? New Sci. 204, 46-47. doi:10.1016/S02624079(09)62827-X.

Salemdeeb, R., zu Ermgassen, E. K. H. J., Kim, M. H., Balmford, A., Al-Tabbaa, A., 2017. Environmental and health impacts of using food waste as animal feed: a comparative analysis of food waste management options. J. Clean. Prod. 140, Part 2, 871-880. doi.org/10.1016/j.jclepro.2016.05.049.

Sanchez-Acosta, C.G., 2011. Comercialización de alimento para perros vía venta directa, caso: Flagacan, Facultad de Ingeniería. La Salle, Ciudad de México, p. 137. http://www.ptolomeo.unam.mx:8080/jspui/bitstream/132.248.52.100/2242/1/Tesis.p df. $(08 / 01 / 2017)$. 
Secretaria de Economía, 2013. Perfil del Mercado de la Bentonita. Coordinación General de Minería. Dirección General de Desarrollo Minero. México, pp. 1-33.

Tongpool, R., Phanichavalit, N., Yuvaniyama, C., Mungcharoen, T., 2012. Improvement of the environmental performance of broiler feeds: a study via life cycle assessment. J. Clean. Prod. 35, 16-24. doi: 10.1016/j.jclepro.2012.05.007.

Vaughn, S.F., Berhow, M.A., Winkler-Moser, J.K., Lee, E., 2011. Formulation of a biodegradable, odor-reducing cat litter from solvent-extracted corn dried distillers grains, Ind. Crops Prod. 34, 999-1002. doi.org/10.1016/j.indcrop.2011.03.005.

Vaughn, S.F., Kenar, J.A., Felker, F.C. Berhow, M.A., Cermak, S.C., Evangelista, R.L.,. Fanta, G.F., Behle, R.W., Lee, E. (2013) Evaluation of alternatives to guar gum as tackifiers for hydromulch and as clumping agents for biodegradable cat litter, Ind. Crops Prod. 43, 798-801. doi.org/10.1016/j.indcrop.2012.09.002.

Voith, V.L., 2009. The impact of companion animal problems on society and the role of veterinarians. Vet. Clin. North Am. Small Anim. Pract. 39, 327-345. doi: 10.1016/j.cvsm.2008.10.014. 